\title{
O Museu Paulista e as concepções de museu em São Paulo
}

Paula Hilst Selli*

\section{Resumo}

Este artigo traz um recorte da pesquisa de mestrado "Crianças, museus e formação de público em São Paulo", concluída na Universidade Estadual Paulista "Júlio de Mesquita Filho" - Unesp, em 2011. O texto a seguir parte das concepções de museu expressadas pelas crianças participantes da pesquisa, para discutir a representação de museu no imaginário do próprio paulistano, e como o Museu Paulista da USP faz parte dessa representação.

Palavras-chave: Museu Paulista. Público. São Paulo.

\section{The Paulista Museum and museums' concept at São Paulo}

This article is a part of master's research, "Crianças, museus e formação de público em São Paulo" made at UNESP in 2011. The following text begins with the research's results about museum concept expressed by the children who took part in the research, in order to debate the population's general concept of museum and which is the role that Museu Paulista, one of the best known museums in the city, plays on this concept.

Key-words: Paulista Museum. Audiences. Sao Paulo

Trabalho com educação em museus e a relação entre museu e público têm se apresentado, nos últimos anos, entre meus principais interesses dentro da área. Conhecer como se dá o início dessa relação, durante a infância, tornou-se um dos focos de meu trabalho. Assim, em minha pesquisa de mestrado ${ }^{1}$, conversei com crianças de quatro escolas localizadas no município de São Paulo, para conhecer suas relações e pensamentos sobre os museus.

O conjunto das respostas das crianças despertou questionamentos tais como: Que representações de museu são essas que temos e passamos adiante, como público, como profissionais, como professores, como instituição? De onde surgem e por que surgem? Como lidamos com elas? Neste artigo, trago um recorte da dissertação que aborda 
justamente esse aspecto da pesquisa, buscando relacionar as concepções de museu que temos em nosso imaginário com a experiência vivida e reforçada em um dos principais museus da cidade.

Notei que, para as crianças que participaram da pesquisa, museu é um lugar que reúne uma grande quantidade de objetos diferentes, no geral relacionados ao passado, sendo uma de suas principais funções ligada à aprendizagem, embora possa servir também ao lazer. Nas descrições físicas do museu feitas pelas crianças ${ }^{2}$, ele aparece quase sempre como grande e/ou bonito.

Embora a representação de museu como espaço de aprendizagem seja bastante abstrata para tal, sua relação com a grandiosidade e beleza das edificações e o agrupamento de objetos, incluindo os antigos, é reforçada nos desenhos que as crianças fizeram para a pesquisa, alguns dos quais reproduzo aqui.

Destaquemos, por ora, o fato de essa representação de museu estar repetidamente relacionada ao passado ${ }^{3}$, ao acúmulo de objetos e a uma imagem de beleza e grandiosidade. Essa representação de museu, e talvez outras, pode estar diretamente relacionada ao fato de $43,15 \%$ das crianças participantes da pesquisa terem citado o Museu Paulista, quando Ihes solicitei o nome de um museu. Esse número se distribuiu em três das quatro escolas pesquisadas, embora em apenas uma delas tenham sido apontados relatos de visita escolar a esse museu. Embora não tenhamos informações da escola, sobre como foi conduzida esta visita ${ }^{4}$, pelos depoimentos dos alunos das outras duas escolas, percebemos que, ainda que as visitas ao Museu Paulista tenham sido feitas fora do âmbito formal de educação, sua presença no imaginário dos respondentes continuava forte. 


\section{Nomes de Museus}
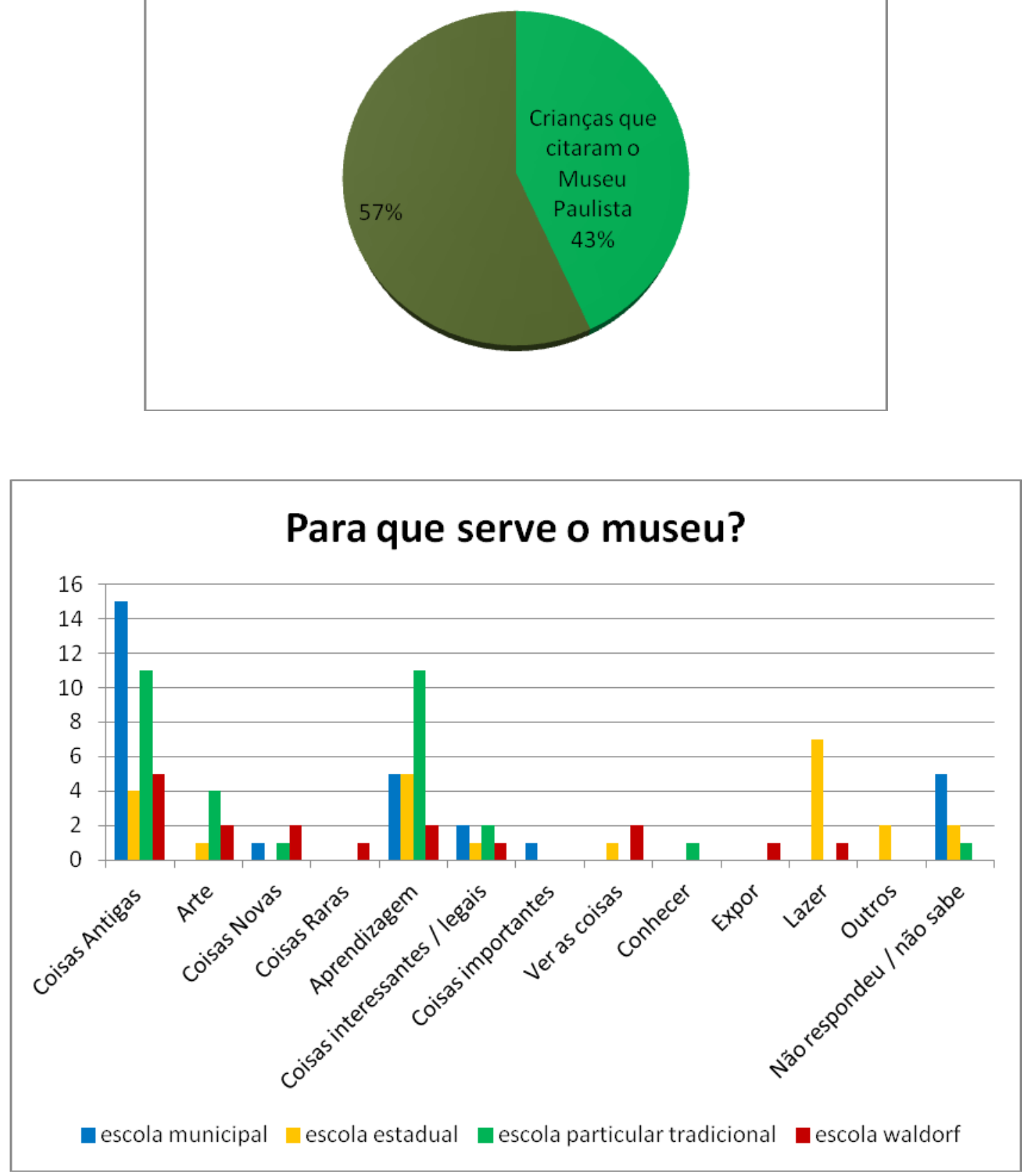

O Museu Paulista é, além de um museu pertencente hoje a uma universidade, um cartão postal e ponto de referência extremamente conhecido na cidade de São Paulo. Sem uma pesquisa aprofundada sobre o assunto, apenas conhecendo o espaço, já é possível relacioná-lo à representação de museu tecida pelas crianças, por ser este um museu histórico, repleto de objetos antigos, sediado em uma edificação imponente e com muitos ornamentos. 
Mas por que o Museu Paulista é tão representativo, na memória dessas crianças? Quando perguntei às crianças se se lembravam do nome de algum museu, os museus mais citados, após o Museu Paulista, foram citados apenas três vezes, enquanto este museu esteve na resposta de 41 crianças $^{5}$. Durante as rodas de conversa que fizemos com cada grupo de crianças, para comentar e discutir as respostas individuais, a instituição do bairro do Ipiranga também apareceu com bastante força e repetidas vezes.

Arrisco-me a dizer que essa não é uma característica da faixa etária pesquisada, mas do paulistano de maneira geral. Para explicar essa colocação, reportarei alguns autores que pesquisaram a história desse museu, seu propósito inicial e o projeto decorativo que sofreu no início do século XX, quando assumiu, em grande parte, sua configuração atual.

Como registrado em diversas publicações (SCHAWRCZ, 1989; UNIVERSIDADE DE SÃO PAULO, 1990; OLIVEIRA, 1995; BREFE, 2005), o edifício onde se encontra o Museu Paulista foi "projetado como monumento de celebração da Independência brasileira" (BREFE, 2005, p. 145), sendo que a ideia de sua construção deu-se poucos anos após a Independência. Embora a proposta existisse desde a década de 1820, sua construção demorou décadas para se realizar.

Cecília Helena de Salles Oliveira (1995) comenta, a partir da obra de Manuel Eufrásio de Azevedo Marques, as diversas e frustradas tentativas de erguer, no sítio do Ipiranga, um monumento que marcasse o local da Independência do Brasil, tentativas essas que se estenderam por quase todo o século XIX. A autora também aponta para o fato de as décadas de 1860 e 1870 terem sido "marcadas pela exteriorização de projetos concernentes à transposição da narrativa histórica e das tradições orais para outros suportes". Segundo ela, "datam de 1862 a inauguração da estátua equestre de D. Pedro I, na Praça da Constituição, e de 1872, a inauguração da escultura em homenagem a José Bonifácio, no Largo de São Francisco, ambas no Rio de Janeiro." (1995, p. 197)

Oliveira segue seu texto com uma série de considerações e questionamentos acerca da situação política da época, especialmente no que diz respeito à relação entre as lideranças locais e a Comissão Central, que teriam influenciado a construção do Monumento do Ipiranga. Foram, nesse ínterim, elaborados os critérios de um concurso público que tinha como objetivo eleger um projeto para o Monumento. As inscrições 
deveriam ser feitas até julho de 1876. Apesar da publicação, esse empreendimento ainda não seria de fato realizado. Em 1884, um novo concurso público seria organizado, mas seus vencedores também não seriam aproveitados (GUILHOTTI, 1990). Ainda nesse ano, é contratado o italiano Tommaso Gaudenzio Bezzi como arquiteto do monumento que começaria a ser construído, finalmente, em 1885, às vésperas da Proclamação da República.

O Museu Paulista, construído, portanto, para ser o monumento paulista à Independência, localizado na já venerada colina do Ipiranga, onde teria sido dado o famoso grito, começou suas atividades oficialmente em 1894, como um museu dedicado principalmente à História Natural (SCHAWRCZ, 1989). Segue, dessa maneira, as tendências dos museus da época, como o Museu Nacional e o Museu Paraense, mas, com exceção de sua grandiosidade arquitetônica, este não seria ainda o "Museu do Ipiranga" que habita a memória paulistana.

Foi a partir de 1917, na gestão de Affonso d'Escragnolle Taunay, que o Museu Paulista conheceu a configuração e simbologia presentes até hoje. Sobre a decoração interna do museu - projeto desse diretor para as comemorações do centenário da Independência -, a ascensão do caráter histórico que ele assumiria e seu papel no estabelecimento da história paulista, como parte geradora e fundamental da formação da nação brasileira, discorrem diversos autores. Isso porque os papéis que essa instituição, seu espaço e história assumem em nosso imaginário estão fortemente vinculados a esse projeto, levado a cabo por Taunay.

Logo nos primeiros anos, o diretor tratou de reservar grande espaço do museu às coleções históricas, dedicando algumas salas especialmente à História Paulista. Embora mantivesse em boas condições as coleções de História Natural, teceu diversas críticas ao seu antecessor, o naturalista Hermann Von Ihering, que, segundo ele, esquecera "que o Palácio do Ipiranga fora construído e concebido como um memorial da Independência brasileira" (BREFE, 2005, p. 88).

Brefe (2005), Chiarelli (1998), Meneses (1990) e Oliveira (1995) são alguns dos autores que, cada um a sua maneira, abordam o enfoque pedagógico do projeto de Taunay, um projeto que tinha como objetivo contar uma determinada versão da História Nacional, 
versão com forte enfoque regional, neste caso, paulista. Apresento a seguir alguns excertos de diversos textos desses autores, que podem nos ajudar a compreender a relevância do projeto de Taunay, para a construção da memória e conceituação sobre o museu e sobre a própria história de São Paulo:

A proposta da construção de um Monumento no Ipiranga. Os argumentos utilizados para justificálo e a maneira pela qual foi concebido apontam para a formulação de uma leitura particular da história do Brasil e de representações sobre a Província de São Paulo que tiveram posteriormente enorme ressonância principalmente no âmbito dos discursos republicanos de fins do século. (OLIVEIRA, 1995, p. 198)

[...] por meio desse investimento direcionado sobre as imagens relativas ao passado paulista, Taunay foi um dos responsáveis pela difusão e fixação da idéia de um nacionalismo paulista, já esboçada pela produção historiográfica do $\mathrm{IHGSP}^{6}$, que vê o paulista, em suas várias gerações bandeirante, tropeiro, cafeicultor - como o responsável pelo progresso não só do estado de São Paulo, mas de todo o país. O espírito aventureiro e desbravador aparecia como a marca de um povo que, desde suas origens, esteve comprometido com o futuro e o progresso ininterrupto da nação brasileira. E essa versão histórica consagrada pela instituição do Ipiranga faz parte, num contexto mais amplo, das investidas da elite social paulista no sentido de se legitimar como força motriz dos destinos nacionais. (BREFE, 2005, p. 110)

Taunay parecia saber que, criando essa mitologia, estava criando as bases de justificação para o domínio dos paulistas sobre o Brasil, para o domínio dos paulistas tradicionais sobre a São Paulo invadida de seus dias.

Seu papel, portanto, era pedagógico. Devia ensinar pelas várias dependências do museu, a superioridade do paulista do presente, pela significação do paulista do passado. (CHIARELLI, 1998, p. 33)

O memorial, portanto, não é somente um monumento arquitetônico, mas a reencarnação figurada de um gesto gerador de nacionalidade e que, pela evocação, permite a celebração, com seus efeitos pedagógicos. (MENESES, 1990, p. 21)

Embora os enfoques desses autores sejam diferentes, é evidente, em seus textos, o caráter proposital e didático do projeto de Taunay, como disseminador de uma ideia de passado construída para enaltecer a participação da província de São Paulo na História Nacional. Não nos cabe aqui aprofundar a crítica às intenções e métodos do antigo diretor, todavia podemos percebê-los como material para estudo e reflexão, não devendo ser simplesmente purgados, mas compreendidos criticamente, como nos aponta Sevcenko: 
Mas, ao invés de contestá-lo pura e simplesmente, o que não faria sentido (uma vez que ele constitui uma dimensão de referência na nossa experiência de vida e as pessoas têm a expectativa desses grandes marcos), a estratégia mais eficiente é desestabilizar a retórica mostrando a sua artificialidade, como discurso fechado. É preciso, pois, apontá-la como mensagem em circuito fechado e desvendar os mecanismos pelos quais ela se reproduz a si própria. Assim, reconhecendo a mensagem, também será possível sentir-se fora dela e, com isso, produzir-se um distanciamento crítico. Numa instituição tão central, na sociedade, como o museu, cabe mais que as coisas tenham certo grau de instabilidade de se deslocar da rigidez que tem um efeito estéril sobre a imaginação. O Museu Paulista, no que ele incorpora de História e significado, como marco da cidade de São Paulo, tem uma posição estratégica exatamente para atuar como ativador, um energizador da reflexão e da imaginação, muito mais do que - como tem sido - um reforçador de conceitos previamente estabelecidos, altamente definidos e fechados em seu próprio circuito de significações. (SEVCENKO, 1990, p. 23).

A partir dessa compreensão crítica, também podemos tentar entender como essa iconografia construída e as histórias do "boca a boca" que transpassam o local do museu continuam a se difundir, de geração em geração, no imaginário da população paulistana. Brefe (2005) relata como a reabertura do Museu Paulista, em 7 de setembro de 1922 ${ }^{7}$, foi cercada de mistério e espetáculo, e como Taunay, naquele mês, divulgou o "novo" museu por meio dos veículos da imprensa da época, anunciando e enaltecendo o fato de, enfim, a história do marco da Independência e do povo paulista estarem devidamente representadas e ao alcance do público.

Desde aquela época, portanto, o Museu Paulista assumia importante papel dentro da cidade, tornando-se, como descreve Oliveira (1995, p. 195) "parte integrante de nossas heranças históricas e culturais. Um dos marcos do espaço urbano paulistano, local a ser visitado e admirado."

Toledo (1990) lembra que o exterior e o interior do museu foram temas de inúmeros cartões postais, desde as primeiras décadas do século XX, o que o ajudou a perpetuar-se no imaginário da cidade. Na mesma publicação, Guilhotti, Lima e Meneses, ao comentarem sobre a urbanização do bairro do Ipiranga, naquela época distante do centro, também refletem sobre os meios de difusão do espaço simbólico da colina do Ipiranga e seu museu: 
O monumento não influenciou, diretamente, a urbanização dessas bandas, mas como espaço celebrativo, de contemplação e lazer, foi sempre responsável por volumoso fluxo de visitantes. Com isso, certamente deve ter acelerado a instalação dos bondes da Light em 1902. [...]

Finalmente, incorporou-se, em definitivo, ao imaginário da cidade, como marco, difundindo-se em livros didáticos e manuais de História, cartões-postais - desde os mais antigos -, álbuns fotográficos, guias, documentos oficiais, suportes publicitários e assim por diante. $\mathrm{O}$ alcance da imagem, porém, ultrapassou as fronteiras da cidade. O palácio, às margens do Ipiranga, integra, sem dúvida, o imaginário nacional. (1990, p. 11)

Dada a dimensão que assumira no imaginário paulistano à época do centenário, dificilmente esse museu passaria despercebido pelos moradores, mesmo nos dias de hoje. De fato, em 1990, Meneses comenta a continuidade da peregrinação ao museu, especialmente na data de 7 de setembro:

Com efeito, esta verdadeira catedral cívica é ainda lugar cultuado por massas de "romeiros" que, particularmente na Semana da Pátria, acorrem ao Ipiranga. As práticas podem ter mudado, assim como os conceitos, expectativas, ideologias, clichês, em torno de núcleos de sentido como dependência/independência, nação, pátria herói, ação, história, memória, etc., etc. Mas a alegoria montada ainda é eficaz. (p. 21)

Ainda hoje, o Museu Paulista recebe um imenso fluxo de visitantes ${ }^{8}$. Ainda hoje, a Semana da Pátria é a semana mais movimentada do Museu, e os funcionários comentam sobre a preferência da população por visitá-lo justo no dia 7 de setembro, ainda que este seja o dia no qual o Museu fique sobrelotado ${ }^{9}$.

O fluxo é tão intenso, que, especialmente nesse dia, o Museu realiza uma pesquisa de público, a cada ano. A intenção da pesquisa é conhecer melhor o perfil dos visitantes da instituição. Na edição de 2010, gentilmente cedida para uso na pesquisa, podemos perceber, num primeiro momento, a maneira como esses visitantes enxergam o Museu, e as informações e crenças que têm sobre ele. Esses dados corroboram o afirmado pelo professor Ulpiano de Meneses, sobre a eficácia da alegoria construída por Taunay, a continuidade da "romaria" de visitantes nos dias atuais, e também se soma à representação de museu expressada por nossas crianças durante a pesquisa.

A simbologia fixada pela população começa com o nome do Museu. Para 59\% dos entrevistados, no dia 7 de setembro de 2010, o nome da instituição era Museu do 
Ipiranga. Um número considerável, mas menor, 38\%, sabia que o nome correto é Museu Paulista da USP, e outros 3\% o associaram ao Palácio de D. Pedro ou o intitularam Museu da Independência. O número de pessoas que identificou o nome corretamente é grande, mas devemos considerar que essa entrevista foi realizada ao final da visita, quando o entrevistado já tivera contato com dados sobre o Museu.

A ideia do Museu como palco de momentos da História Nacional transparece, quando se pergunta aos entrevistados sobre a finalidade da construção daquele edifício. Percentuais muito semelhantes (36\% e 33\%) identificaram essa função como sendo, respectivamente, a de um monumento para a celebração da Independência, e como residência da família real. Números razoáveis, mas menores ainda, responderam que o edifício fora construído para ser um museu ou para ser sede do governo.

Esses dados ilustram um pouco as representações que o público tem desse Museu, muitas vezes ainda equivocadas. Essas representações aparecem ligadas a uma simbologia histórica que valoriza a possibilidade de se estar em locais onde viveram ou estiveram figuras importantes, onde talvez tenham sido tomadas decisões relacionadas aos rumos da História Nacional. Lugares dotados, posteriormente, de uma aura de nobreza e distinção, locais de culto e peregrinação quase religiosa, construídos por iniciativas como a de Taunay e que se perpetuaram nas conexões identitárias que a população estabeleceu com esses espaços no decorrer dos anos.

As colocações de Meneses e essa representação do Museu e seus objetos como preservação do cenário onde ocorreram atos heroicos, configurando uma certa aura "sagrada" a esse espaço, são reafirmadas, mais uma vez, quando 30\% dos respondentes informou ter ido ao Museu naquele dia simplesmente porque era 7 de setembro.

Acredito que essa ideia que se tem do Museu Paulista e seu espaço no Ipiranga faz parte do imaginário de um percentual bem maior do que o encontrado na pesquisa. Isso porque a pesquisa foi realizada na saída do Museu, ou seja, após a visita, onde se espera que os visitantes já tenham tomado contato com mais informações sobre o espaço, sua origem e função. Além disso, trata-se de uma pesquisa de público visitante, ou seja, não se pode, com ela, abarcar a totalidade da ideia que a população em geral, não visitante, tem 
daquele espaço. Nessa outra população, não visitante, o mais provável é que as distorções entre imaginário e realidade sejam ainda maiores.

Dessa forma, somando a representação que se tem em geral sobre o Museu Paulista, sua história, suas cifras impressionantes de visitação e o fato de esse museu ter sido citado por quase metade das crianças participantes de nossa pesquisa, trago para reflexão a possibilidade de a representação de museu assumida por essas crianças e, possivelmente, por boa parte da população de São Paulo, estar fundamentada em tudo que o Museu Paulista representou e representa para a população paulistana.

O museu é "grande e bonito" para as crianças, em grande parte, porque o Museu Paulista, conhecido delas, é grande, imponente e repleto de ornamentações cuidadosamente colocadas. O museu "é antigo, histórico e cheio de objetos do passado", em grande parte, porque é este, hoje, o acervo do Museu Paulista. Por isso, nos desenhos das crianças $^{10}$, aparecem armas, louças, bonecas, cartas. Além disso, vários desenhos trazem claramente ou a tela Independência ou Morte (1888), de Pedro Américo, ou espaços como a fachada do Museu, seu saguão de entrada, ou o monumento que fica em frente a ele, identificados pelo nome ou não, mas com elementos arquitetônicos claramente relacionados ao mesmo ${ }^{11}$.

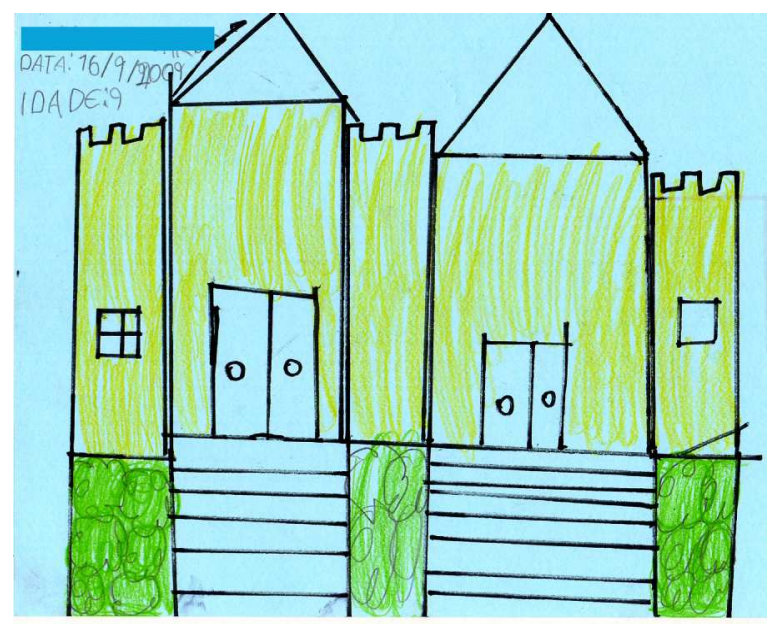

FIGURA 1 - Desenho de criança participante da pesquisa

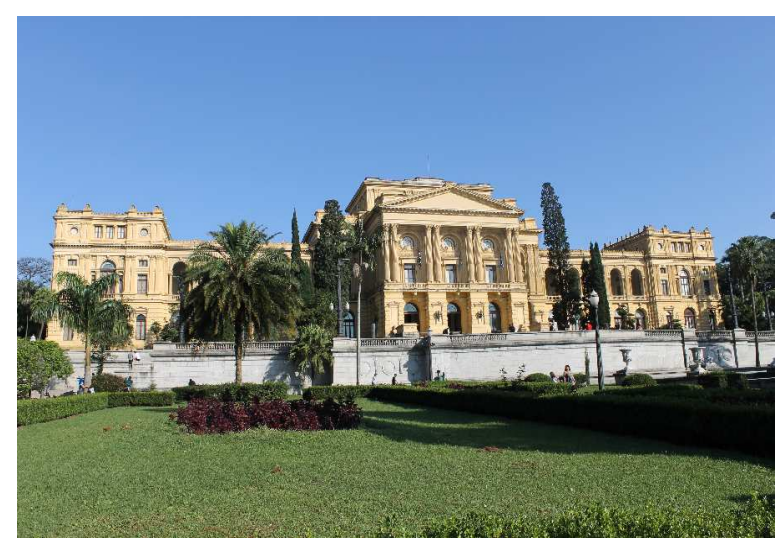

FIGURA 2 - Museu Paulista da USP. Fotografia de V. Pires 


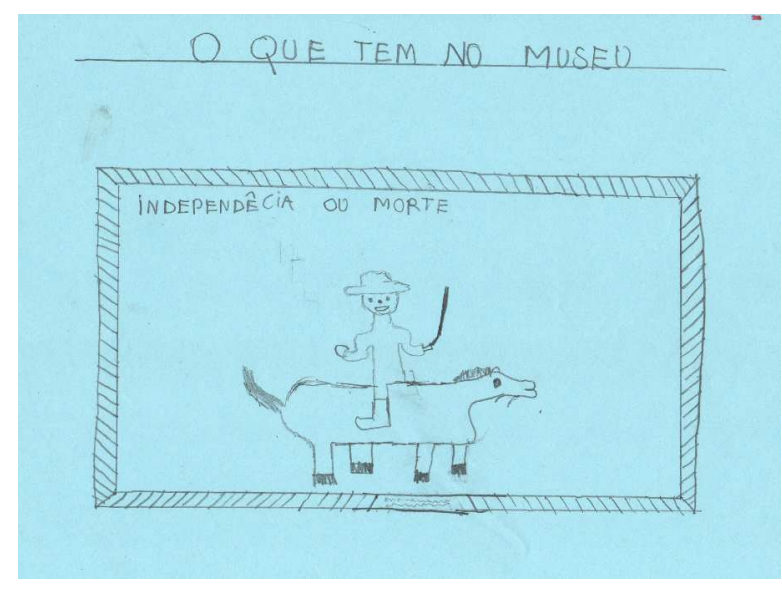

FIGURA 3 - Desenho de criança participante da pesquisa

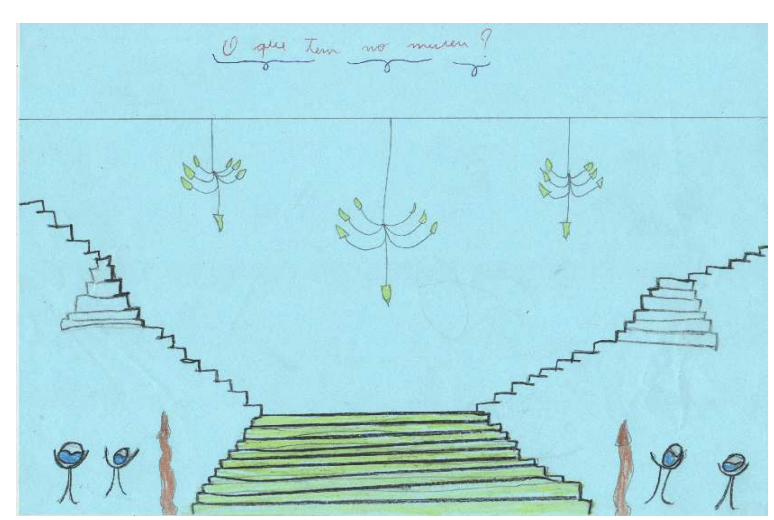

FIGURA 5 - Desenho de criança participante da pesquisa

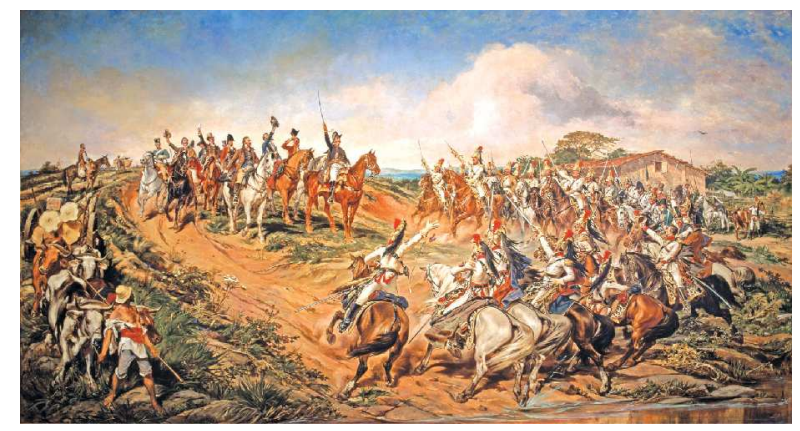

FIGURA 4 - "Independência ou Morte!" Pedro Américo, 1888. Imagem do Arquivo do Museu Paulista da USP

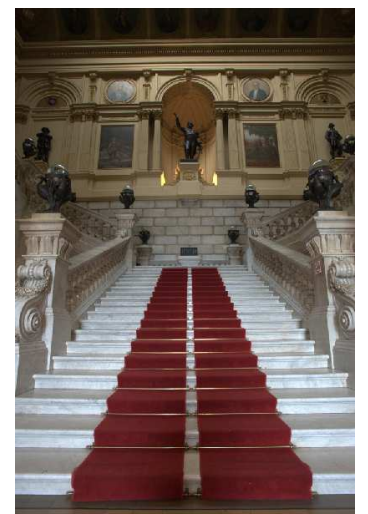

FIGURA 6 - Saguão de entrada. Imagem do Arquivo do Museu Paulista da USP

Indo além, a própria relação, estabelecida pelas crianças, entre museu e aprendizagem pode ter sua origem na representação de museu que nasce da experiência com o Museu Paulista da USP. Isso, porque as crianças da escola ${ }^{12}$ em que se relacionou mais diretamente museu e aprendizagem haviam passado recentemente por uma visita a este museu com a escola. O Museu Paulista também é bastante requisitado ${ }^{13}$ por grupos escolares em geral, que veem seu conteúdo como fortemente relacionado ao currículo escolar. Nas Orientações Curriculares para Ensino Fundamental I da Rede Municipal de Ensino podemos destacar, nas expectativas de aprendizagem referentes à área de conhecimento intitulada Natureza e Sociedade, os temas propostos para o $5^{\circ}$ ano: "Quem somos" e "Viver na cidade de São Paulo", que, por si só, já estabelecem relação direta com o conteúdo do Museu Paulista.

Se analisarmos com atenção cada objetivo de aprendizagem proposto para essa etapa do ensino fundamental, inclusive alguns dos anos anteriores, podemos apontar uma relação 
ainda mais estreita entre o currículo e o acervo do Museu, já que o currículo desse ciclo parte da comunidade da criança - bairro e cidade -, para trabalhar os diferentes conteúdos propostos, por exemplo:

- Conhecer a história da cidade usando diferentes fontes: escritas, orais, iconográficas (fotos, desenhos, pinturas), musicais etc., e estudo do meio.

- Organizar a história da cidade, e sua relação com a história brasileira, por meio de texto e de linha do tempo, discernindo acontecimentos de curta, média e longa duração.

- Identificar e comparar objetos que permaneceram ou se modificaram na paisagem urbana da cidade em diferentes períodos.

- Identificar dados sobre a população de São Paulo em representações pictóricas e mapas temáticos.

- Identificar processos de produção, de conservação, de circulação de alimentos que abastecem a cidade, e os sujeitos históricos neles envolvidos, considerando suas mudanças e permanências no tempo.

- Identificar espaços de memórias da cidade (museus, exposições...) (SÃO PAULO, 2007)

Esse documento está também em consonância com os Parâmetros Curriculares Nacionais de História e Geografia (SECRETARIA DE EDUCAÇÃO FUNDAMENTAL, 1997 ), para $1^{\mathrm{a}}$ a $4^{\mathrm{a}}$ séries, especialmente os do segundo ciclo ${ }^{14}$. Há nesse documento orientações para que o professor opte por estudos que relacionem a realidade local com outras, de diferentes localidades ou com um âmbito maior. Assim, o aluno poderá, conhecendo seu contexto e outros, diferentes do seu, compreender as questões inerentes à sua comunidade, identificando-se e percebendo-se diante do todo. Ora, o projeto do Museu Paulista, com seu enfoque na História de São Paulo e, a partir dela, do Brasil, não parece oferecer justamente isso?

Voltando à representação de museu que emergiu das falas e desenhos das crianças participantes da pesquisa, podemos concluir que, em grande parte, essa representação está relacionada aos museus que elas conhecem, ou seja, embora composta de uma série de imagens diferentes de museus, essa representação se funda principalmente em um museu tradicional, um dos mais antigos do país, e que conheceu poucas alterações durante as últimas décadas.

Assim, a representação de museu que habita o imaginário de boa parte dessas crianças é a própria imagem do Museu Paulista da USP, um museu que, usando as palavras delas, 
"é grande, bonito e cheio de coisas antigas". Um local onde se pode "aprender as coisas do passado".

Que reflexões, nós, profissionais de museus e de educação, podemos desenvolver, a partir da representação de museu dessas crianças e de sua provável origem em um único museu? É um pouco assustador, perceber a força que emana de um único espaço, nas relações e processos identitários, entre as pessoas, a cidade e seus espaços públicos.

É preocupante, para os profissionais dos outros museus, em sua diversidade de tipologias, edificações e meios comunicacionais, que a ideia de museu se restrinja tanto. Mais preocupante deve ser, imagino, para os profissionais do próprio Museu Paulista, pela ciência da responsabilidade que sua comunicação com o público envolve. Principalmente porque têm consciência dos equívocos que povoam a mente da população, sobre a própria origem e natureza do museu, e de como é difícil modificá-los.

Não há outro meio de ampliar essa representação de museu presente no imaginário da população, que não seja o contato direto entre as pessoas e os museus. As pessoas precisam chegar aos diferentes tipos de museus, pois só assim compreenderão a existência dessas diferenças. Além disso, é necessária uma atenção especial ao modo como esses museus recebem as pessoas, pois isso refletirá no reforço ou reformulação das representações de museu já existentes.

Para que as pessoas cheguem aos diferentes tipos de museus, estes também precisam chegar às pessoas. Precisam aparecer. Precisam convidá-las a entrar. Em sua gestão, Taunay colocou o Museu Paulista na mídia, mas hoje não costumamos ler ou ouvir sobre museus, em mídias não especializadas. Embora os museus tenham partido para atitudes mais proativas em relação ao seu público, elas ainda são modestas, numa cidade com a amplitude de São Paulo. Bom seria que as atividades cotidianas dos diferentes museus pudessem receber tanta atenção da imprensa, quanto as megaexposições temporárias. De qualquer forma, repercussões desse nível necessitariam ser conduzidas muito cuidado, para não transformarem em espetáculo superficial o que tem potencial de ser uma relação mais aprofundada, de identidade e pertencimento, entre a população e os museus. 
A boa notícia, inferida também da pesquisa com as crianças, é que uma nova representação de museu começa a aparecer. Embora de maneira difusa e bem menos frequente, algumas crianças já apontam que os museus têm coisas novas, coisas diferentes, animais, dispositivos de ciência, ações como narradores contando histórias etc. Várias delas já conseguem perceber que, no museu, podem aprender e também se divertir, embora, de maneira geral, as duas funções ainda apareçam em respostas separadas.

A citação de museus de ciência, a grande bilheteria do recente Museu da Língua Portuguesa ${ }^{15}$ e a aparição, nos desenhos, do Museu do Futebol (que também recebeu, por ocasião de sua fundação, em setembro de 2008, grande atenção da imprensa) nos apontam para um futuro no qual a representação de museu possa escapar do restrito "grande, bonito e cheio de coisas antigas". Talvez, daqui a algumas décadas, a concepção de museu encontrada seja outra, totalmente diferente.

Para concluir esta reflexão, referente às representações de museus que temos e gostaríamos de ter, registro um alerta para que fiquemos atentos a essa mudança. Teremos ganhos, se todos os tipos de museus, grandes ou pequenos; tradicionais, comunitários ou tecnológicos; urbanos ou rurais; históricos, artísticos ou de ciências, puderem encontrar seu espaço nessa nova representação de museu. Teremos ganhos, com uma verdadeira ampliação das representações de museus no imaginário da população, mas não haverá ganho nenhum, com uma simples troca de dominâncias.

Essa ampliação do conceito de museu poderia trazer maior aproximação entre a população e os museus da cidade, já que, ao perceber as instituições museológicas de modo mais diversificado, também seria possível vê-las como capazes de satisfazer as necessidades específicas de grupos variados de pessoas. Assim, o público frequente e ocasional dos museus poderia se estender e se diversificar também.

Por outro lado, se simplesmente passarmos, da ideia de museu como guardião de objetos estáticos e antigos, para a ideia de museu como espaço povoado por dispositivos tecnológicos, ou seja, se um único museu, ainda que novo, continuar a ser responsável pela representação de museu existente no imaginário da população, não haverá enriquecimento da ideia de museu, não haverá, portanto, a ampliação de pensamento, 
que tanto poderia contribuir para o desenvolvimento do campo museológico e da relação entre as populações e seus museus.

Este risco deve ser considerado, uma vez que os museus que têm ganhado espaço, na fala da população e na mídia, são os que apresentam expografia digital. O que quero dizer, utilizando exemplos da própria cidade e levando em consideração os públicos dessas instituições, é que de nada vale apenas trocar o Museu Paulista pelo Museu da Língua Portuguesa. Com uma simples troca como essa, a representação de museu presente no imaginário da população continuaria tão restrita quanto hoje.

\section{Notas}

(1) SELLI, Paula Hilst. Crianças, museus e formação de público em São Paulo. Dissertação de Mestrado apresentada ao Instituto de Artes da Universidade Estadual Paulista (UNESP). São Paulo, 2011.

(2) Ao pedir que as crianças descrevessem o museu, 17,89\% abordou a aparência do museu. Adjetivos como grande e bonito foram bastante utilizados por elas.

(3) Durante a pesquisa, as crianças relacionaram o museu ao passado e às coisas antigas, muitas vezes e em perguntas diferentes. Cerca de $25 \%$ das crianças apresentou essa resposta nas perguntas sobre a descrição do museu e sobre os motivos pelos quais as pessoas vão aos museus. Ao perguntar às crianças para que serve o museu, esse percentual foi ainda maior: quase $37 \%$. Ao perguntar às crianças por que gostavam de ir aos museus, o número de crianças que disse gostar de ir ao museu para ver objetos do passado, ou aprender sobre o passado foi ainda de $17 \%$.

(4) É importante explicar que a pesquisa priorizou, o tempo todo, a fala e experiência da própria criança, e não os discursos de cada uma das escolas. Assim, sabemos de algumas visitas a museus, promovidas pela instituição escolar, pelas falas dos alunos, como foi o caso do Museu Paulista e do Museu Afro Brasil, como experiências vividas e relatadas por eles, da mesma forma como relataram suas visitas a museus com os pais, suas descobertas e seus interesses. O foco sempre foi a experiência e opinião da criança, e não o projeto de visitas a instituições culturais de cada escola. Pelas crianças, soubemos, por exemplo, que a visita com familiares é mais presente e mais forte nas lembranças da maior parte dos participantes da pesquisa.

(5) A pesquisa envolveu um total de 95 crianças de cerca de 9 anos de idade, de quatro escolas do município de São Paulo, sendo duas públicas (uma estadual e uma municipal) e duas privadas (uma de pedagogia tradicional e uma Waldorf). A opção por trazer representantes de escolas com gestão e proposta pedagógica tão diversas teve como objetivo proporcionar um universo mais rico de pesquisa, que contasse com a fala de diferentes públicos escolares. As turmas foram selecionadas de acordo com a faixa etária, disponibilidade de horário na escola e autorização dos pais. A metodologia envolveu um jogo-questionário para as respostas individuais, uma roda de conversa e um desenho, em cada uma das turmas. Para mais detalhes sobre as características das turmas e estratégias metodológicas, sugerimos a consulta à dissertação que deu origem a este artigo.

(6) Instituto Histórico e Geográfico de São Paulo. 
(7) Brefe ainda nos fala sobre uma série de atos comemorativos do centenário da independência em São Paulo. 0 conjunto desses atos, especialmente os da Serra do Mar, corrobora a ideia de a nação ter se desenvolvido a partir de São Paulo e pelo trabalho dos paulistas.

(8) Em 2009, foram mais de 280 mil visitantes. Informação concedida em entrevista por e-mail com Denise Peixoto responsável pelo Serviço Educativo do Museu.

(9) Tanto entre 1998 e 2002, quando trabalhei como bolsista e autônoma no museu, quanto mais recentemente, quando fui conversar sobre a visitação e atendimento atuais, para a pesquisa, as pessoas que trabalham no museu comentaram sobre o forte fluxo de visitantes no dia 7 de setembro.

(10) Foi solicitado às crianças que fizessem um desenho com o tema "como é o museu", sem indicação de que museu seria esse. A preferência de muitas crianças em representar o Museu Paulista é reflexo de sua experiência mais próxima com esse museu.

(11) As referências a esse museu, interna ou externamente, só não apareceram nos desenhos de uma das escolas pesquisadas. Nessa escola, o Museu Paulista também não foi citado pelas crianças, no jogo das perguntas.

(12) Embora a referência ao Museu Paulista tenha aparecido fortemente em três das quatro escolas pesquisadas, apenas uma delas relatou visita escolar recente a esse museu. A mesma escola apresentou maior quantidade de respostas relacionando museu à aprendizagem.

(13) Em 2010, por exemplo, 885 escolas visitaram o museu, o que ultrapassa os 39 mil alunos. Informação concedida em entrevista por e-mail com Denise Peixoto - responsável pelo Serviço Educativo do Museu.

(14) Trata-se, aqui, do segundo ciclo do Ensino Fundamental I, ou seja $4^{\circ}$ e $5^{\circ}$ anos, mas que, à época de publicação dos PCNs, ainda eram $3^{\mathrm{a}}$ e $4^{\mathrm{a}}$ séries, pois ainda não existia o Ensino Fundamental de nove anos.

(15) 387.600 visitantes em 2009. Informação concedida em entrevista por e-mail com Marina Toledo, responsável pelo Serviço Educativo do Museu.

\section{Referências Bibliográficas}

ALMEIDA, Adriana Mortara. Os visitantes do Museu Paulista: um estudo comparativo com os visitantes da Pinacoteca do Estado e do Museu de Zoologia. In: Anais do Museu Paulista. São Paulo, v.12. jan./dez. 2004. p. 269-306.

BRASIL. Secretaria de Educação Fundamental. Parâmetros Curriculares Nacionais: História e Geografia $\left(1^{\mathrm{a}}\right.$ a $4^{\mathrm{a}}$ séries ). Brasília: MEC/SEF, 1997.

BREFE, Ana Claudia Fonseca. O Museu Paulista: Affonso de Taunay e a Memória Nacional 1917 - 1945. São Paulo: Editora UNESP: Museu Paulista, 2005. p.87-163 e 287-291

CHIARELLI, Tadeu. Anotações sobre Arte e História no Museu Paulista. In: FABRIS, Annateresa (org.) Arte e Política: Algumas Possibilidades de Leitura. Belo Horizonte: Fapesp Editora c/Arte, 1998 (p. 21-46). 
ELIAS, Maria José. Revendo o nascimento dos museus no Brasil. In: Revista do Museu de Arqueologia e Etnologia, São Paulo, 2:139-145, 1992.

GUILHOTTI, Ana Cristina; LIMA, Solange Ferraz de; e MENESES, Ulpiano T. Bezerra de. Às margens do Ipiranga: um monumento-museu. In: Às margens do Ipiranga 1890-1990. Exposição do Centenário do edifício do Museu Paulista da USP. São Paulo: Museu Paulista - USP, 1990. p. 9-11.

MENESES, Ulpiano T. Bezerra de. O Salão Nobre do Museu Paulista e o Teatro da História. In: Às margens do Ipiranga 1890-1990. Exposição do Centenário do edifício do Museu Paulista da USP. São Paulo: Museu Paulista - USP, 1990. p. 20-21.

MOTA, Carlos Guilherme. O Museu Paulista e o Panteão da Independência. In: Às margens do Ipiranga 1890-1990. Exposição do Centenário do edifício do Museu Paulista da USP. São Paulo: Museu Paulista - USP, 1990. p. 22.

MUSEU Paulista da USP. Relatório de Pesquisa de Público - 7 de setembro de 2010. São Paulo: [s.n.] 2010.

MUSEU Paulista da USP. Site do Museu. Disponível em:<http://www.mp.usp.br/> Acesso em: 20 jul. 2010.

OLIVEIRA, Cecília Helena de Salles. O espetáculo do Ipiranga: reflexões preliminares sobre o imaginário da Independência. In: Anais do Museu Paulista. São Paulo. N. Ser. v. 3 p. 195-208 jan./dez. 1995.

SÃO PAULO [MUNICÍPIO] Secretaria Municipal de Educação. Diretoria de Orientação Técnica. Orientações curriculares e proposição de expectativas de aprendizagem para o Ensino Fundamental: ciclo I. São Paulo: SME/DOT, 2007.

SELLI, Paula Hilst. Crianças, museus e formação de público em São Paulo. Dissertação de Mestrado apresentada ao Instituto de Artes da Universidade Estadual Paulista (UNESP). São Paulo, 2011.

SEVCENKO, N. Museu Paulista: História, mito, crítica. In: Às margens do Ipiranga 1890 - 1990. Exposição do Centenário do Edifício do Museu Paulista da USP. São Paulo: Museu Paulista - USP, 1990. p.22-23

SCHWARCZ, Liliam Moritz. Nascimento dos Museus Brasileiros: 1870 - 1910. In: História das Ciências Sociais no Brasil. São Paulo: Vértice Ed. Revista dos Tribunais /ldesp, p 20-71, 1989.

SUANO, Marlene. O que é Museu. São Paulo: Brasiliense, 1986.

TOLEDO, Benedito Lima de. Museu Paulista: a imagem difundida. In: Às margens do Ipiranga 1890-1990. Exposição do Centenário do edifício do Museu Paulista da USP. São Paulo: Museu Paulista - USP, 1990. p. 25.

UNIVERSIDADE DE SÃO PAULO. Às margens do Ipiranga 1890 - 1990. Exposição do Centenário do Edifício do Museu Paulista da USP. São Paulo: Museu Paulista - USP, 1990. 


\section{Créditos}

*Licenciada em Educação Artística com habilitação em Artes Plásticas pela ECA-USP, mestre em Artes pelo Instituto de Artes da UNESP. Educadora do Museu Lasar Segall - IBRAM/MinC. Endereço eletrônico: paulahilst@yahoo.com 